\title{
ATIK SULARDAN AĞIR METALLERİN KÖMÜR YIKAMA ATIKLARI KULLANILARAK UZAKLAŞTIRILMASI
}

\author{
Ünzile YENIAL ${ }^{1}$ (ORCID: 0000-0002-1165-7222 )* \\ Gülay BULUT ${ }^{1}$ (ORCID: 0000-0001-7016-8077)
}

\begin{abstract}
ÖZ
Bu çalışmada ağır metal içeren endüstriyel atık su sorununa kömür yıkama tesislerinden çıkan ince boyutlu kömür atıkları kullanılarak çözüm bulunmaya çalışılmıştır. Kömür yıkama atıkları içeriğindeki killi ve karbonlu yapıdan dolayı adsorptif özellikleri bulunmaktadır. Atık suların içerisinde bulunan $\mathrm{Pb}, \mathrm{Zn}, \mathrm{Cu}$ ve $\mathrm{Cd}$ metallerinin kömür yıkama atıklarına adsorpsiyonu, $\mathrm{pH}$, temas süresi ve başlangıç konsantrasyon parametreleri ile araştırılmıştır. Ayrıca metallerin hangi mekanizması ile giderildiğinin belirlenmesi amacıyla adsorpsiyon deneylerine paralel çöktürme deneyleri yapılmıştır. Adsorpsiyon izotermlerinden Langmuir, Freundlich, Temkin ve Dubinin-Radushkevich modelleri uygulanmış, bunlardan Langmuir ve Freundlich iyi sonuç verdiği bulunmuştur. Adsorpsiyonun fiziksel olduğu ve hesaplanan Gibss serbest enerjisine göre kendiliğinden geliștiği bulunmuştur. $\mathrm{Bu}$ çalışma ile kömür hazırlama tesislerinden üretilen yıkama atıklarının atık sulardan ağır metal uzaklaştırılmasında kullanılabilecek etkili bir adsorbent olduğu belirlenmiştir.
\end{abstract}

Anahtar kelimeler: kömür, atık, atıksu, metal, adsorpsiyon, çöktürme, langmuir, freundlich

\section{HEAVY METALS REMOVAL FROM WASTEWATERS BY USING COAL WASHERY WASTES}

\begin{abstract}
In this study, the heavy metal containing waste waters problem is solved with fine coal wastes produced from coal washing plants. Coal washery wastes have adsorptive properties due to their clayey and carbonaceous structure. The adsorption of $\mathrm{Pb}, \mathrm{Zn}, \mathrm{Cu}$ and $\mathrm{Cd}$ metals in waste water onto coal washery waste is investigated by $\mathrm{pH}$, contact time and initial concentration parameters. Besides, precipitation tests were carried out to determine the metal removal mechanism is either precipitation or adsorption depending on $\mathrm{pH}$. Langmuir, Freundlich, Temkin and Dubinin-Radushkevich models have been applied as the adsorption isotherms, Langmuir and Freundlich have been found to give the best correlations. It is found that adsorption mechanism is physisorption and the Gibbs energy reaction is spontaneous. As a result of this study, the tailings of the coal preparation plants could be employed as an efficient adsorbent for removal of metal ions from wastewater.
\end{abstract}

Keywords: coal, waste, wastewater, metal, adsorption, precipitation, langmuir, freundlich

\section{GİRIȘ}

Madencilik, cevher hazırlama ve metalürjik prosesler katı, sıvı ve gaz atıklara neden olurlar. Maden atıkları kazı atıkları, proses atıkları, metalurjik atıklar, maden suları, gaz atıkları olarak sınıflandırılabilir. Birçok maden atıkları özellikle metalik maden endüstrisinden ortaya çıkan atıklar çeşitli konsantrasyonlarda metal

${ }^{*}$ Corresponding author / Sorumlu yazar. Tel.: 02122857360 ; e-mail / e-posta: yenial@itu.edu.tr 
içermektedir. Metalik cevherler çeşitli kimyasal bileşiklerde oksitli veya sülfürlü metaller içerebilmektedir. Bu atıkların yanı sıra yapılan işlemler neticesinde madencilik suları (kirlenmiş yüzey ya da yer altı suları, asit maden drenaj1), proses suları (çeşitli kimyasallar içerebilen öğütme ve zenginleştirme sonucu ortaya çıkan), atık suları (metalürjik işlemler neticesinde ortaya çıkan) gibi sular da bir kirlilik sorunu olarak ortaya çıkmaktadır $[1,2]$.

Endüstriyel atık su arıtımı çevre açısından özel ve önemli bir konudur. Atık sulardan ağır metallerin giderimi için çeşitli fiziksel, kimyasal ve biyolojik arıtma yöntemleri kullanılabilir hatta bazı durumlarda birden fazla prosesin etkin bir kombinasyonu gerekmektedir. Ağır metal iyonlarının su ortamında giderilmesinde kullanılan arıtma teknikleri olarak; kimyasal çöktürme, filtrasyon, kimyasal oksidasyon, iyon değiştirme, mikroorganizma kullanma, ters osmoz, flotasyon, aktif çamur sistemleri, lamella çökeltimi, aktif karbon adsorpsiyonu gibi yöntemler kullanılmaktadır [3].

Ağır metal atıklarını içeren sularda, geleneksel metotlar için fazla kararlı olan kirleticilerin giderme veriminin düşük ve maliyetinin yüksek olmasından dolayı adsorpsiyon yöntemi ilgi görmektedir. Adsorpsiyon prosesi, metal adsorbent etkileşimi, adsorbentin yüzey alanı, tane boyutu, sıcaklık, pH ve temas süresi gibi pek çok fiziko-kimyasal faktörün etkisi altındadır [4]. Taneli veya toz halindeki aktif karbon, organik bileşiklerin uzaklaştırılmasındaki yeteneği nedeni ile adsorbent olarak yaygın olarak kullanılmaktadır. Atık sulardan metallerin uzaklaştırılmasında aktif karbondan başka kil, bentonit, kliniptilolit, zeolit, doğal demir ve alüminyum oksitler kullanılmaktadır [5, 6]. Bunun yanında endüstriyel birer atık olan uçucu kül [7], kırmızı çamur [8], cüruf [2], ve pirit artıkları [9] günümüzde hem çevresel kirliliği azaltmak hem de atık suları temizlemek için alternatif adsorbentler olarak araştırmalarda kullanılmıştır.

Türkiye taş kömürü ve linyit rezervleri olan ve ticari olarak üreten bir ülke olup 1.3 milyar ton bitümlü kömür rezervi vardır ve yılda ortalama 6 milyon ton üretim yapılmaktadır. 2015 yılında toplam kömür tüketimi (asfaltit, bitümlü şist ve taş kömürü) 61.929 .516 ton olarak belirlenmiştir [10]. Kömür atıkları yakma sonu atıkları ve yıkama atıkları olarak ayrılır. Yıkama atıklarında atığı oluşturan mineraller doğal haldedir, yakma sonunda ise değişime uğramıştır. Kömürün yan taşı kil ve şistlerdir [11]. Kömür yıkama atıklarında kömür kırılarak iri, ince ve şlam boyutlarında $(0.5 \mathrm{~mm}$ altı) çeşitli gravite yöntemleri kullanılarak zenginleştirilir. Yıkama sonucunda ince boyutlu şlam boyutundaki kömürler, flotasyonla kazanılabilir olmasına rağmen, çoğunlukla tikinerlerde çöktürülür, susuzlandırılır ve bazı tesisler tarafından kaliteli kömürle karıştırılarak termik santrallere satılır, satılamayanlar ise düzenli olarak depolanır.

Kömür atıkları yüksek oranda refrakter kil içeriyorsa tuğla fabrikalarında, $\mathrm{CaCO}_{3}$ içeriyorsa çimento yapımında değerlendirilebilirler. Ancak yüksek oranda inorganik kükürt içeren bu atıkların uzun süre nemli ortamlarda depolanması asit maden drenajına yol açmakta, kuru ortamda saklanmalarında ise kendinden yanma/tutuşma gibi sorunlara yol açmaktadır.

Kömür atıkları eğer bir önlem alınmazsa asit maden drenajı gibi bir çevre problemine yol açabileceği gibi, uygun prosesler sayesinde atık su problemine çözüm de olabilir. Literatürde atık sulardan civa, kurşun ve kadmiyum uzaklaştırılmasında düşük ranklı (kaliteli)Türkiye kömürleri kullanılarak başarılı sonuçlar elde edilmiştir [12]. Uçurum (2008) tarafından yapılan çalışmada [13], G.L.İ. Ömerler lavvarına ait besleme malı, ara ürün ve atıkları kullanılarak $\mathrm{Pb}$ ve $\mathrm{Cu}$ ağır metal adsorpsiyonuna tane irilik dağılımının etkisi araştırılmıştır ve sonucunda kömür atığ1 numunesinin $\mathrm{Pb}$ için $9.30 \mathrm{mg} / \mathrm{g}, \mathrm{Cu}$ için $7.69 \mathrm{mg} / \mathrm{g}$ metal iyon adsorplama kapasitesi değerleri ile öne çıktığı tespit edilmiştir. Literatürde kömür atıklarının atık sulardan metal uzaklaştırılmasında kullanıldığı çalışmalar oldukça azdır ve detaylı araştırmalar yapılabilir.

$\mathrm{Bu}$ çalışmada kömür yıkama atıkları kullanılarak atık sulardaki ağır metallerin giderilme etkinliği çöktürme yöntemi ile karşılaştırmalı olarak araştırılmıştır.

\section{MATERYAL VE METOT}

Bu çalışmada kömür yıkama atığı olarak Zonguldak Deka firmasına ait kömür lavvarının -0.2 mm boyutlu kömür atığı kullanılmıştır. $1 \mathrm{~mm}$ üstü kömürler ağır ortam ayırıcılarıyla yıkanırken $-1 \mathrm{~mm}$ malzeme ağır ortam ayırmasına girmeden siklon vasıtasıyla $0.2 \mathrm{~mm}$ boyutundan ayrılmaktadır. Siklon üst akımı (-0.2 mm) doğrudan tikinere gönderilip çöktürülmektedir. Deneylerde tikinere gönderilen bitümlü kömür şlamı kullanılmıştır. Numune $\% 42$ pülpte katı oranındadır, deneylerde kurutulduktan sonra kullanılmıştır. Bu numuneye yapılan elek analizine göre $\mathrm{d}_{80}$ boyutunun $0.12 \mathrm{~mm} \mathrm{~d} \mathrm{~d}_{50}$ boyutunun ise $0.038 \mathrm{~mm}$ olduğu saptanmıştır. Deneylerde kömür atıkları orijinal boyutunda kullanılmıştır. Şekil 1'de elekaltı eğrisi verilmektedir.

Kömür yıkama atığının toplam kül içeriği \%42.4'dür. Malzemenin \%50'sini olușturan 0.038 mm boyut altında kül içeriği \%64.48'dir. Bu da kömür numunesindeki kül yapıcı maddelerden kil grubunun bu boyutta toplandığını göstermektedir. Kömür numunesinin kuru bazda üst 1sıl değeri $4197 \mathrm{kcal}$, uçucu madde miktarı $\% 20.23$, sabit karbon miktarı \%37.33 olarak bulunmuştur. Numunenin kimyasal analizinde major oksitler için XRF minör elementler ICP kullanılmıştır ve sonuçları Tablo 1'de verilmiştir. Bu analize göre kömür yıkama 
atığı ağırlıklı olarak karbon içerikli malzeme (kömür), silikat ve alüminyum oksitlerden oluşmaktadır. Şekil 2'de kömür yıkama atıklarının XRD analizi yer almaktadır. Bu analiz göre kömür yıkama atıkları kuvars, biotit, kaolin, muskovit minerallerinden oluşmaktadır. Kömürdeki karbon amorf olması nedeniyle XRD analizinde tespit edilememiştir. Şekil 3'te kömür yıkama atıklarının SEM görüntüsü verilmiştir. Şekilde de görüldüğü gibi kömür yıkama atıkları farklı boyutlarda heterojen, laminer bir yapıya sahiptir. BET (Brunauer, Emmett, Teller) yüzey alanı analizine göre, kömür yıkama atığının yüzey alanı $6.55 \mathrm{~m}^{2} / \mathrm{g}$, por çapı $10.18 \mathrm{~nm}$ ve por hacmi 0.016 $\mathrm{cm}^{3} / \mathrm{g}$ olarak bulunmuştur.

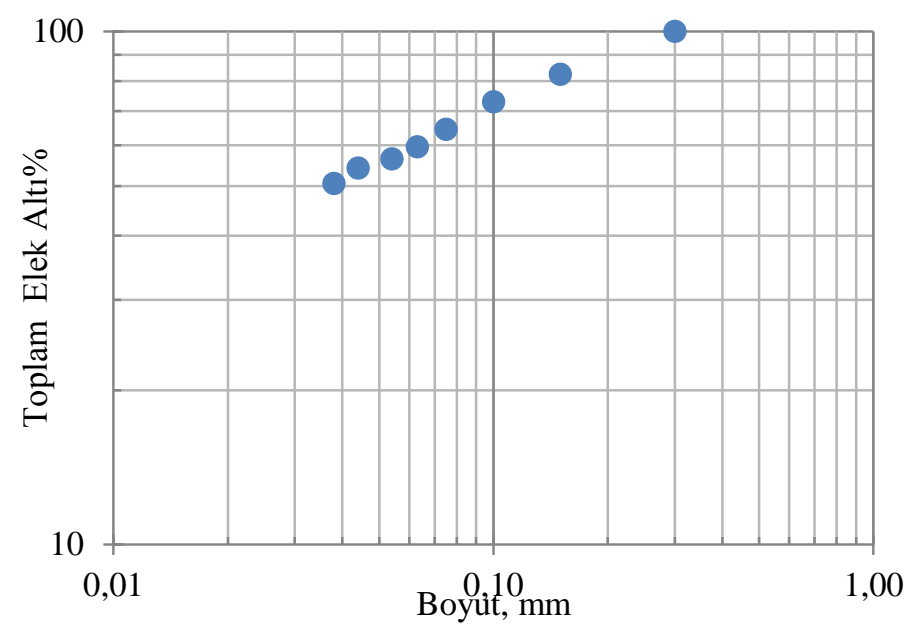

Şekil 1. Kömür yıkama atığının boyut analizi

Tablo 1. Kömür yıkama atığının kimyasal analizi

\begin{tabular}{|c|c|c|c|}
\hline Bileşik & İçeriği \% & Element & İçeriği, mg/L \\
\hline $\mathrm{Al}_{2} \mathrm{O}_{3}$ & 10.86 & $\mathrm{As}$ & 3 \\
\hline $\mathrm{BaO}$ & 0.04 & $\mathrm{Ba}$ & 410 \\
\hline $\mathrm{CaO}$ & 0.66 & $\mathrm{Cd}$ & $<0.5$ \\
\hline $\mathrm{Cr}_{2} \mathrm{O}_{3}$ & $<0.01$ & $\mathrm{Co}$ & 8 \\
\hline $\mathrm{Fe}_{2} \mathrm{O}_{3}$ & 1.37 & $\mathrm{Cr}$ & 15 \\
\hline $\mathrm{K}_{2} \mathrm{O}$ & 1.74 & $\mathrm{Cu}$ & 38 \\
\hline $\mathrm{MgO}$ & 0.89 & $\mathrm{Ga}$ & $<10$ \\
\hline $\mathrm{MnO}$ & 0.02 & $\mathrm{La}$ & $<10$ \\
\hline $\mathrm{Na}_{2} \mathrm{O}$ & 0.07 & $\mathrm{Mn}$ & 212 \\
\hline $\mathrm{P}_{2} \mathrm{O}_{5}$ & 0.04 & $\mathrm{Ni}$ & 24 \\
\hline $\mathrm{SO}_{3}$ & 0.07 & $\mathrm{P}$ & 120 \\
\hline $\mathrm{SiO}_{2}$ & 23.05 & $\mathrm{~Pb}$ & 25 \\
\hline $\mathrm{SrO}$ & $<0.01$ & $\mathrm{Sr}$ & 55 \\
\hline $\mathrm{TiO}$ & 0.46 & $\mathrm{Th}$ & $<20$ \\
\hline $\mathrm{C}$ & 49.83 & $\mathrm{~V}$ & 18 \\
\hline Toplam & 96.05 & $\mathrm{U}$ & $<10$ \\
\hline $\mathrm{KK}$ & 56.77 & $\mathrm{Zn}$ & 44 \\
\hline
\end{tabular}

Deneylerde kullanılan ayrı ayrı $\mathrm{Pb}, \mathrm{Cd}, \mathrm{Cu}, \mathrm{Zn}$ içeren metal çözeltileri, analitik saflıktaki metal tuzlarından $\mathrm{Pb}\left(\mathrm{NO}_{3}\right)_{2}, \mathrm{Cu}\left(\mathrm{SO}_{4}\right), \mathrm{Zn}\left(\mathrm{SO}_{4}\right), \mathrm{Cd}\left(\mathrm{SO}_{4}\right)$ (Merck) gerekli miktarı 1L saf suda çözündürülüp nitrik asit ilave edilerek hazırlanmıştır. Stok çözeltiler $1000 \mathrm{mg} / \mathrm{L}$ konsantrasyonda hazırlanmış, deneylerde gerekli konsantrasyonlar için seyreltilerek kullanılmıştır. pH ayarlaması için $\mathrm{HCl}$ ve $\mathrm{NaOH}$ kullanılmıştır. pH ölçümü için Hanna marka (8314) pH metre kullanılmış, her deney öncesinde pH 7 ve pH 4 buffer çözeltileriyle kalibre edilmiştir. Deneylerde çözeltileri karıştırmak için manyetik karıştırıcı (IKA) kullanılmıştır. 


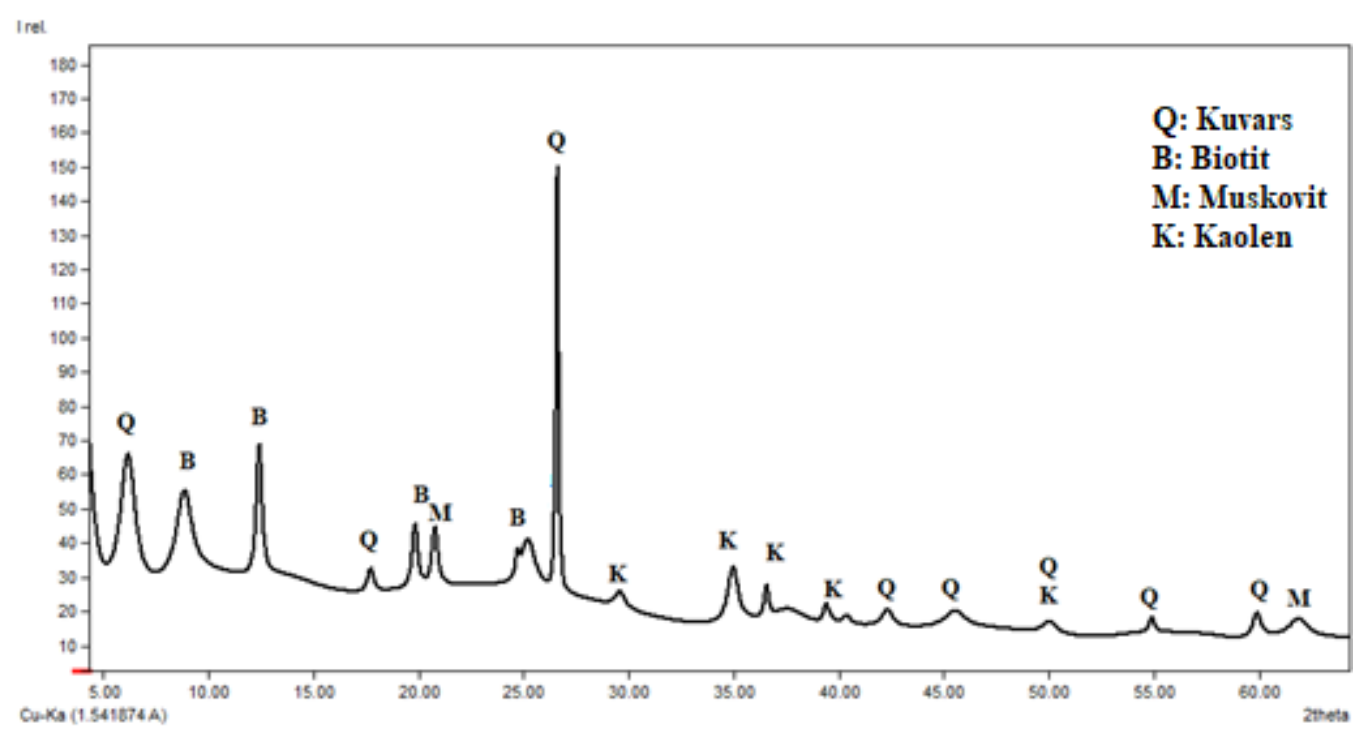

Şekil 2. Kömür yıkama atığının XRD analizi.

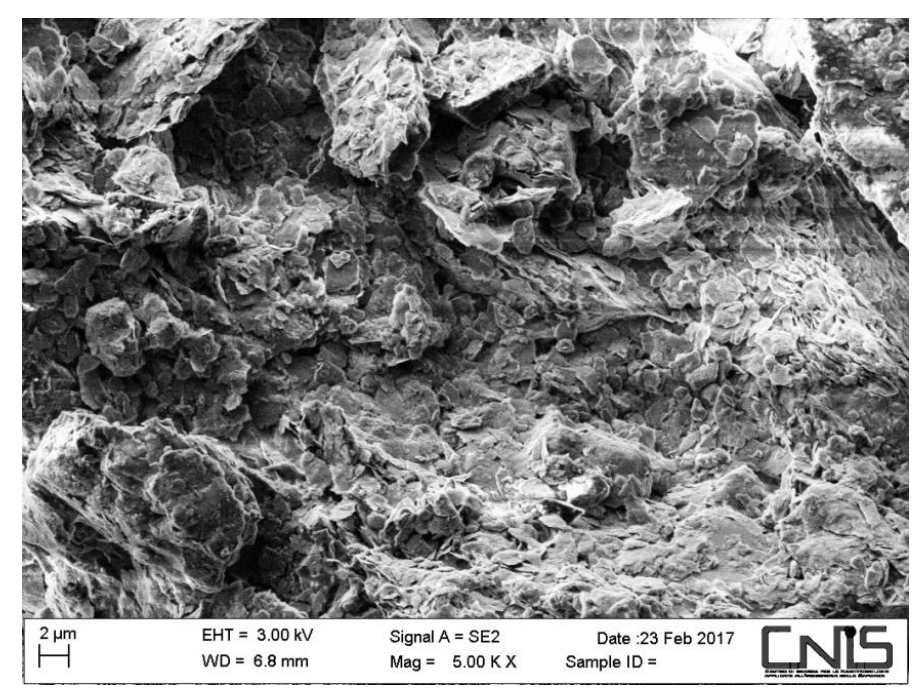

Şekil 3. Kömür yıkama atıklarının SEM görüntüsü

\subsection{Metot}

Çöktürme deneylerinde başlangıç konsantrasyonu 20 mg/L olan Pb, Cd, Cu, Zn metal iyonları, NaOH ile pH'sı yükseltilerek 30 dakika boyunca karıştırılmıştır. Karıştırma sonrasında çözelti 10 dakika dinlenmeye bırakılmış üzerindeki berrak çözeltiden örnek alınarak çözeltide kalan metal konsantrasyonu analiz edilmiş böylece çöktürme ile metal giderim miktarları tespit edilmiştir.

Adsorpsiyon deneylerinde aksi belirtilmedikçe $20 \mathrm{mg} / \mathrm{L}$ konsantrasyondaki metal iyonları, $5 \mathrm{~g} / \mathrm{L}$ konsantrasyonunda adsorbent ile bir araya getirilip 30 dak karıştırılmıştır. Karıştırma düzeneği beher, manyetik balık ve manyetik karıştırıcıdan oluşmaktadır. Karıştırma sonrasında $0.22 \mu \mathrm{m}$ açıklıklı disk filtreler kullanılarak katı sıvı ayrımı yapılmış, çözeltide kalan metal konsantrasyonu analiz edilmiştir. Sonuçlar, verim (\%) ve katı üzerinde adsorplanan metal konsantrasyonu $\mathrm{qm}(\mathrm{mg} / \mathrm{g})$ hesaplanarak değerlendirilmiştir. Bu verilerin hesaplanış1 denklem 1 ve 2'de verilmiştir:

$$
\begin{gathered}
\text { Verim }=\frac{\mathrm{Ci}-\mathrm{Ce}}{\mathrm{Ce}} * 100 \\
q m=\frac{(\mathrm{Ci}-\mathrm{Ce}) * V}{M}
\end{gathered}
$$

Denklemlerde; Ci: başlangıç adsorbat konsantrasyonu (mg/L), Ce: deney sonunda çözeltide kalan adsorbat konsantrasyonu (mg/L), V: Çözelti hacmi (L), M: adsorbent miktarı (gr) ifade etmektedir. Adsorpsiyon 
deneylerinde sırasıyla pH, temas süresi, başlangıç konsantrasyonunun etkisi araştırılmıştır. Bu kapsamda değişen parametreler yeri geldikçe metin içerisinde belirtilmiştir.

Katıların ve sulu çözeltilerin analizleri XRF ve ICP yöntemi ile yapılmıştır. Tane boyut analizleri $0.038 \mathrm{~mm}$ üstünde elekler vasıtasıyla yapılmıştır. XRD analizi D8 Advance Bruker-XRD cihazı ile yaptırılmıştır. Analizin yorumlaması ve pik eşleşmesi için Match! 2 aylık ücretsiz deneme sürümü programı kullanılmıştır. BET yüzey alanı, por çapı ve hacmi analizleri Gemini VII 2390t BET cihazı ile azot ortamında yapılmıştır. Tanelerin morfoloji, tane şekli ve büyüklüğü için HR FESEM Zeiss Auriga Scanning Electron Microscopy (SEM) cihazı kullanılmıştır.

\subsection{Adsorpsiyon İzotermleri}

Adsorpsiyon izotermleri, adsorpsiyon sistemlerinin dizaynı ve analizi için kullanılan temel araçlardandır. İzotermler, sabit sıcaklıktaki bir adsorpsiyon prosesinin dengeye ulaştığ adsorplayabileceği madde miktarı ve akışkan fazdaki madde konsantrasyonu arasındaki ilişkiyi verir. Langmuir izotermi ise tek tabakalı homojen adsorpsiyonu açıklamak için kullanılmaktadır. Langmuir izoterminde adsorpsiyon, adsorbat başlangıç konsantrasyonu ile birlikte lineer olarak artar. Maksimum doyma noktasında, yüzey tek tabaka ile kaplanmakta ve yüzeye adsorbe olmuş adsorbat miktarı sabit kalmaktadır. Ayrıca, bu izotermde adsorpsiyon enerjisi uniformdur. Adsorpsiyon hızı adsorbat konsantrasyonu ve yüzey üzerinde bulunan aktif yerler ile doğru orantılıdır. Freundlich adsorpsiyon izotermi, tek tabaka kaplanması ile sinırlı değildir. Adsorbent yüzeyi adsorpsiyon alanları ve enerjisi bakımından heterojendir. Yani adsorbatın derişimi arttıkça adsorplanan miktar artar. Adsorpsiyonu tamamen ampirik olarak veren Freundlich izoterminde; adsorplanan miktarı ile denge derişimi arasında üstel bir bağıntı vardır. Temkin ve Pyzhev (1940) bazı dolaylı adsorbe olan maddeler arasındaki etkileşimleri, adsorpsiyon izotermlerine etkilerini göz önünde bulundurmuşlar ve bu etkileşimlerden dolayı tabakadaki tüm moleküllerin adsorpsiyon 1sısının, yüzeyin kaplanmasıyla doğrusal olarak azalacağını öne sürmüşlerdir. Dubinin-Radushkevich (D-R) izotermi adsorpsiyonun fiziksel ve kimyasal özellikleri hakkında bilgi sahibi olmamızı sağlar. Bunun yanında D-R izotermi tek tip gözenek yapısına sahip adsorbent yüzeylerde gerçekleşen adsorpsiyonu açıklamakla beraber adsorpsiyon eğrisinin karakteristik özellikleri adsorbentin gözenek yapısına göre değişmektedir [14-17]. Adsorpsiyon izoterm modellerine ait eşitlikler Tablo 2'de verilmektedir. Buna göre denklemlerdeki sabitler Ce: denge anında çözeltide kalan adsorbat konsantrasyonu (mg/L), qe: denge anında adsorbentin üzerinde yüklenmiş olan adsorbat miktarı (mg/g), Qm: maksimum adsorplanma miktarı (mg/g), b: Langmuir izoterm sabiti (L/mg), Kf: Freundlich izoterm sabiti, n: adsorpsiyon yoğunluğu, $\mathrm{A}_{\mathrm{T}}$ : Temkin izotermi denge anında bağlanma sabiti $(\mathrm{L} / \mathrm{g})$, bt: Temkin izoterm sabiti $(\mathrm{L} / \mathrm{mg})$, R: evrensel gaz sabiti $(8.314 \mathrm{~J} / \mathrm{mol} \mathrm{K})$; T: sicaklık $(\mathrm{K}), \mathrm{k}_{\mathrm{ad}}$ : Dubinin-Radushkevich izoterm sabiti $\left(\mathrm{mol}^{2} / \mathrm{Kj}^{2}\right), \quad \varepsilon$ : Dubinin-Radushkevich izoterm sabiti, qs: teorik izoterm doyma kapasitesini (mg/g) ifade etmektedir.

Tablo 2. Adsorpsiyon izotermlerine ait eşitlikler

\begin{tabular}{|c|c|c|c|}
\hline Izoterm model & Formülü & Lineerleştirilmiş Formülü & Eğri \\
\hline Langmuir & $q e=\frac{Q m \cdot b \cdot C e}{1+b \cdot C e}$ & $\frac{C e}{q e}=\frac{1}{Q m . b}+\frac{C e}{Q m}$ vs Ce & $\log q \mathrm{ge}$ vs $\log \mathrm{Ce}$ \\
\hline Freundlich & $q e=K f C e^{1 / n}$ & $\log q e=\log K f+\frac{1}{n} \log C e$ & qe vs $\ln \mathrm{Ce}$ \\
\hline Temkin & $q e=\frac{R T}{b t} \ln A_{T} C e$ & $q e=\frac{R T}{b t} \ln A_{T}+\frac{R T}{b t} \ln C e$ & $\ln (\mathrm{qe}) \mathrm{vs} \varepsilon^{2}$ \\
\hline $\mathrm{D}-\mathrm{R}$ & $q e=(q s) \exp \left(-\mathrm{k}_{a d} \varepsilon^{2}\right)$ & $\ln (q e)=\ln (q s)-\mathrm{k}_{a d} \varepsilon^{2}$ & \\
\hline
\end{tabular}

\section{BULGULAR VE TARTIŞMA}

\section{1 pH'nın etkisi}

pH iyonların türlerini ve adsorbentlerin yüzey yüklerini belirler ve dolayısıyla adsorpsiyonda önemli bir parametredir. Bu nedenle de pH çalışmaları kömür yıkama atıkları kullanılarak en uygun adsorpsiyon koşullarını belirlemek amacıyla pH 3-11 arasında gerçekleştirilmiştir.

Kömür yıkama atıkları ile yapılan pH'ya bağlı adsorpsiyon deney sonuçları Şekil 4'de gösterilmiştir. Kömür yıkama atıkları ile pH'ya bağlı yapılan deneylerde, $\mathrm{Pb}$ giderimi $\mathrm{pH} 3$ 'de 0 iken $\mathrm{pH}$ 4'de \%97.4 olmuş ve $\mathrm{pH}$ 
7.5'a kadar artmış daha sonra pH 10'da \%89.1'e gerilemiştir. Zn giderim verimi pH 7'den sonra \%99'lara ulaşmaktadır. $\mathrm{Cu}$ giderim verimi $\mathrm{pH} 3$ 'de \%16.3 iken, $\mathrm{pH}$ 7'den itibaren \%99 verimler elde edilmektedir. Cd giderimi pH 3'de 0 iken, $\mathrm{pH} 7$ 'den sonra \%97 verimle giderilmiş ve $\mathrm{pH}$ arttıkça \% 09 'lara ulaşmıştır.

Şekil 5'de adsorpsiyon ve çöktürme deney sonuçları karşılaştırmalı olarak sunulmuştur. Düşük pH'larda adsorpsiyon metal uzaklaştırılmasında etkin mekanizma iken, pH yükseldikçe bunun yerini çöktürme mekanizması almaktadır. Çinko uzaklaştırılmasında asidik pH'da çöktürme etkili olurken bazik pH'larda çöktürme kadar adsorpsiyonun da etkili olduğu görülmektedir. Bakır uzaklaştırılmasında ise asidik ve bazik pH'da da adsorpsiyon etkili mekanizmadır. Kurşun uzaklaştırılmasında ise çöktürme genellikle etkili olurken, adsorpsiyonun da pH 9'a kadar etkili olduğu görülmektedir. Kadmiyum uzaklaştırılmasında de pH 7'ye kadar sadece adsorpsiyon etkili iken, $\mathrm{pH}$ 7'nin üzerinde çöktürmede etkili olmakta, $\mathrm{pH}$ 11'de metal giderimi tamamen çöktürme ile sağlanmaktadır.

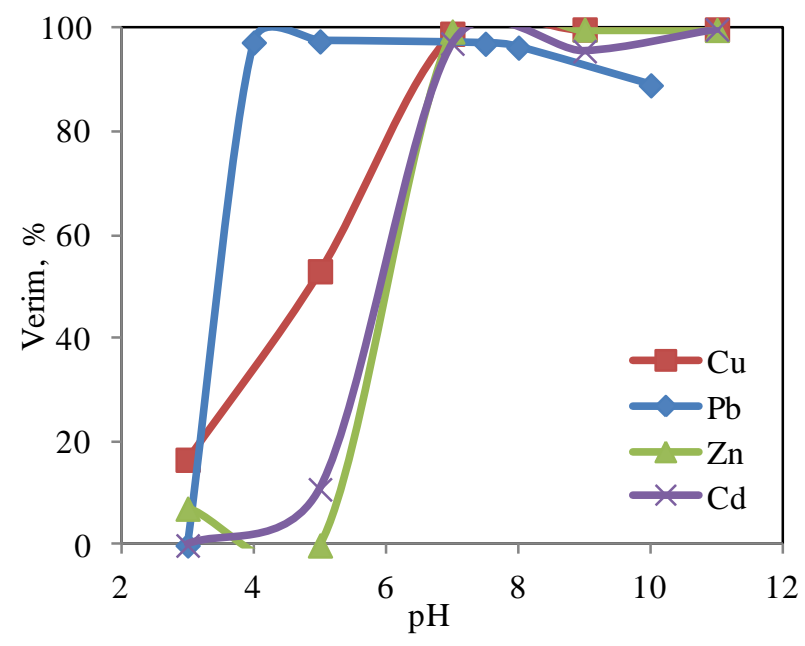

Şekil 4. pH’ya bağlı ağır metallerin adsorpsiyonu
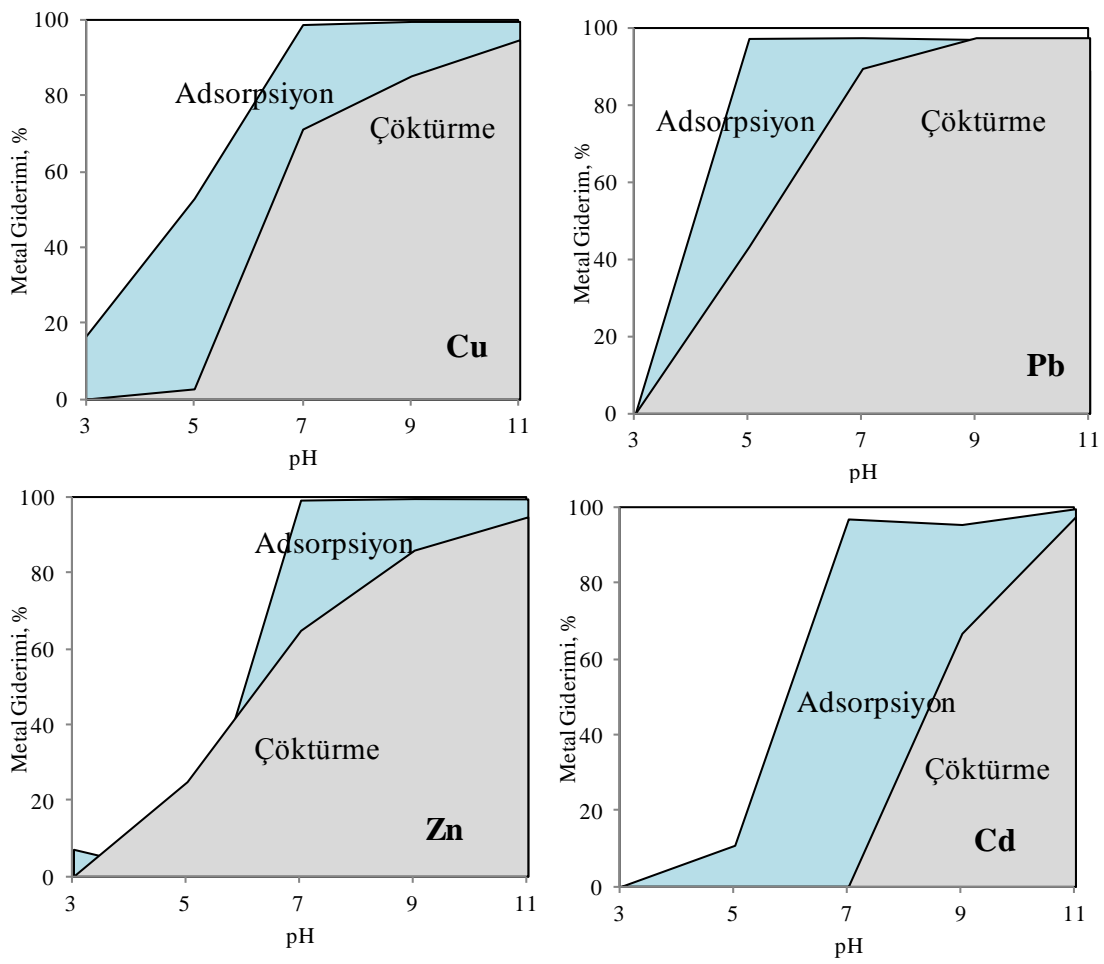

Şekil 5. pH’ya bağlı ağır metallerin adsorpsiyon/çöktürme karşılaştırması 


\subsection{Temas Süresinin Etkisi}

Adsorpsiyonda temas süresinin etkisinin incelendiği çalışmalarda $\mathrm{pH}$ 5'de $5 \mathrm{~g} / \mathrm{L}$ adsorbent miktarında deneyler yapılmıştır. Bu deneylerde metal iyonlarından $\mathrm{Pb}$ seçilerek deney yapılmıştır. Elde edilen sonuçlar Şekil 6'da görülmektedir. Buna göre $20 \mathrm{mg} / \mathrm{L}$ başlangıç konsantrasyonu ile yapılan deneyde kömür yıkama atığı ile 24 saat sonunda $\% 83$ verim elde edilmiştir.

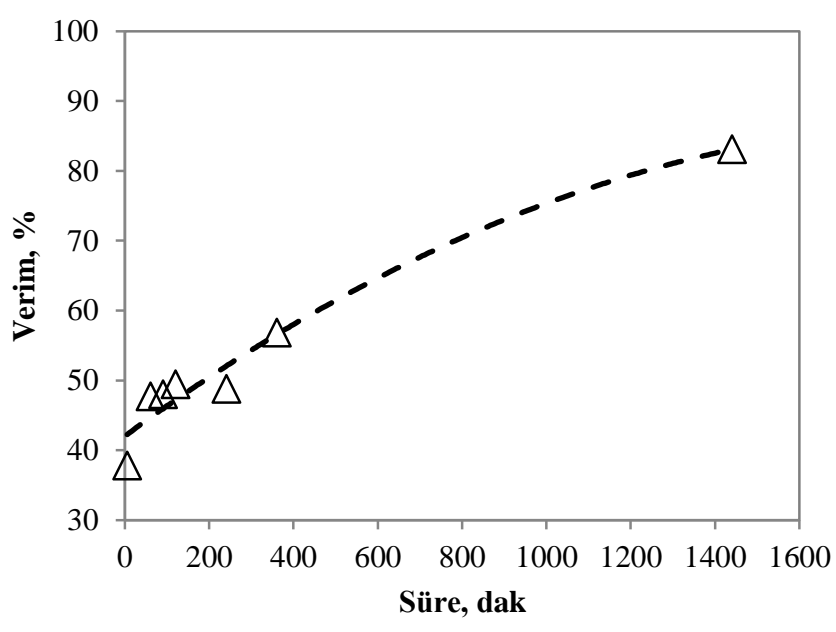

Şekil 6. Temas süresinin kurşun adsorpsiyonuna etkisi

\subsection{Başlangıç Konsantrasyonunun Etkisi}

Adsorpsiyonda başlangıç konsantrasyonunun etkisinin incelendiği çalışmalarda pH 5'de $1 \mathrm{~g} / \mathrm{L} 120 \mathrm{dk}$ sürede kömür yıkama atığı ile yapılan deneylerde iyon konsantrasyonu $20 \mathrm{mg} / \mathrm{L}$ ile $2000 \mathrm{mg} / \mathrm{L}$ arasında değiştirilmiştir. Elde edilen sonuçlar Şekil 7'da verilmektedir. Buna göre maksimum Pb kapasitesi 310 mg/g olarak bulunmuştur.

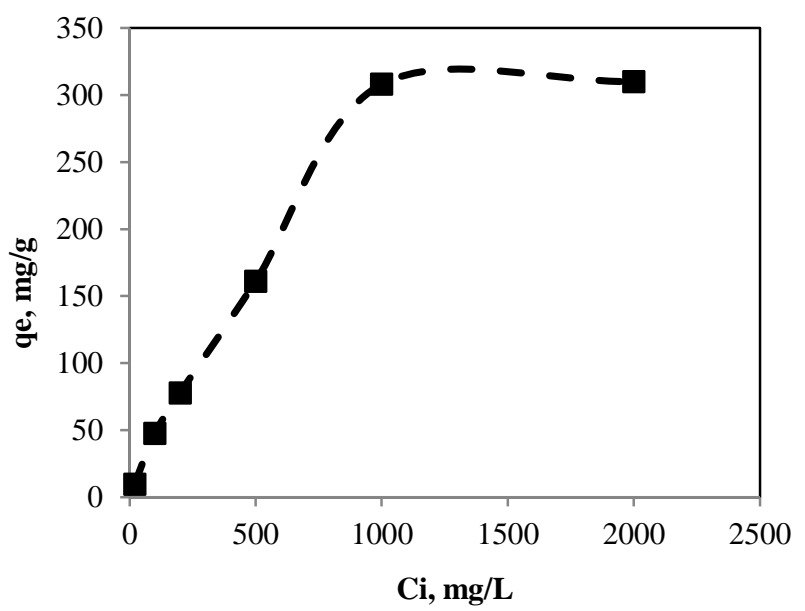

Şekil 7. Kurşun konsantrasyonun değişiminin adsorpsiyonuna etkisi

\subsection{Adsorpsiyon İzotermleri}

Kurşunun kömür yıkama atıkları tarafından adsorpsiyonunda Langmuir, Freundlich, Temkin ve DubininRadushkevich (D-R) adsorpsiyon izoterm modelleri uygulanmış, elde edilen modeller Şekil 8'de gösterilmiştir. Adsorpsiyon izoterm modellerine ait hesaplanan parametreler Çizelge 3'de verilmektedir. Bütün adsorpsiyon modellerinin korelasyonları karşılaştırıldığında $\mathrm{R}^{2}$ değerleri büyükten küçüğe doğru Langmuir $>$ Freundlich $>$ Temkin $>$ D-R olarak sıralanmaktadır. Sonuç olarak kurşunun kömür yıkama atıkları ile adsorpsiyonu Langmuir izoterm modeline daha uygun olduğu görülmüştür. 
Yapılan hesaplamalara göre (Langmuir sabiti qmax) kömür yıkama atıklarının maksimum kapasitesinin 327.8 $\mathrm{mg} / \mathrm{g}$ olduğu bulunmuştur. Ayrıca adsorpsiyonun elverişliliğini bulmak için boyutsuz ayırma sabiti RL (denge parametresi) hesaplanır (Eşitlik 3) [18]:

$$
\mathrm{RL}=1 / 1+\mathrm{b} \mathrm{C}_{\mathrm{i}}
$$

Burada, $\mathrm{C}_{\mathrm{i}}$ adsorbatın başlangıç derişimi $(\mathrm{mg} / \mathrm{L}), \mathrm{b}$ adsorpsiyon enerjisini ifade eden Langmuir sabitidir. $0<\mathrm{RL}<1$ ise adsorpsiyon prosesinin elverişli olmadığını, $\mathrm{RL}=1$ proses sürecinin doğrusal olduğunu, $\mathrm{RL}=0$ ise adsorpsiyon prosesinin geri dönüşsüz olduğunu ifade eder. $C_{i}$ konsantrasyonlarına bağlı olarak hesaplanan $R L$ değerlerinin başlangıç iyon konsantrasyonu arttıkça 0.80'den 0.04'e düştüğü bulunmuştur. Buna göre başlangıç iyon konsantrasyonunun artması adsorpsiyonun daha elverişli olmasını sağlamaktadır.

Freundlich modelinin de çok yüksek korelasyon katsayısı olması nedeniyle, adsorpsiyonun aynı zamanda heterojen olduğu ve farklı adsorpsiyon tabakalarının olduğunu göstermektedir. Ayrıca n>1 olmasından dolayı, kurşun iyonunun kömür yıkama atıkları ile adsorpsiyonu uygundur.

Adsorpsiyon deneylerinden elde edilen sonuçların D-R izotermine uygulanması ile adsorpsiyonun ortalama enerjisi, E ( $\mathrm{kJ} / \mathrm{mol})$, hesaplanabilir. Bu değeri hesaplamak için denklem 4 kullanılmaktadır.

$$
\mathrm{E}=\left[\frac{1}{\sqrt{-2 \mathrm{~K}}}\right]
$$

E değeri adsorpsiyonun fiziksel ve kimyasal mekanizması hakkında fikir vermektedir. Eğer E değeri, 8-16 $\mathrm{kJ} / \mathrm{mol}$ değerleri arasında veya daha büyük bir değere sahipse adsorpsiyon kimyasal olarak gerçekleşmektedir, ancak E değeri $8 \mathrm{~kJ} / \mathrm{mol}$ 'den daha düşük ise adsorpsiyon fiziksel karakterdedir. Bu sistemde hesaplanan E değeri $1.17 \mathrm{kj} / \mathrm{mol}$ bulunmuş olduğundan adsorpsiyon mekanizmasının fiziksel olduğu söylenebilir.

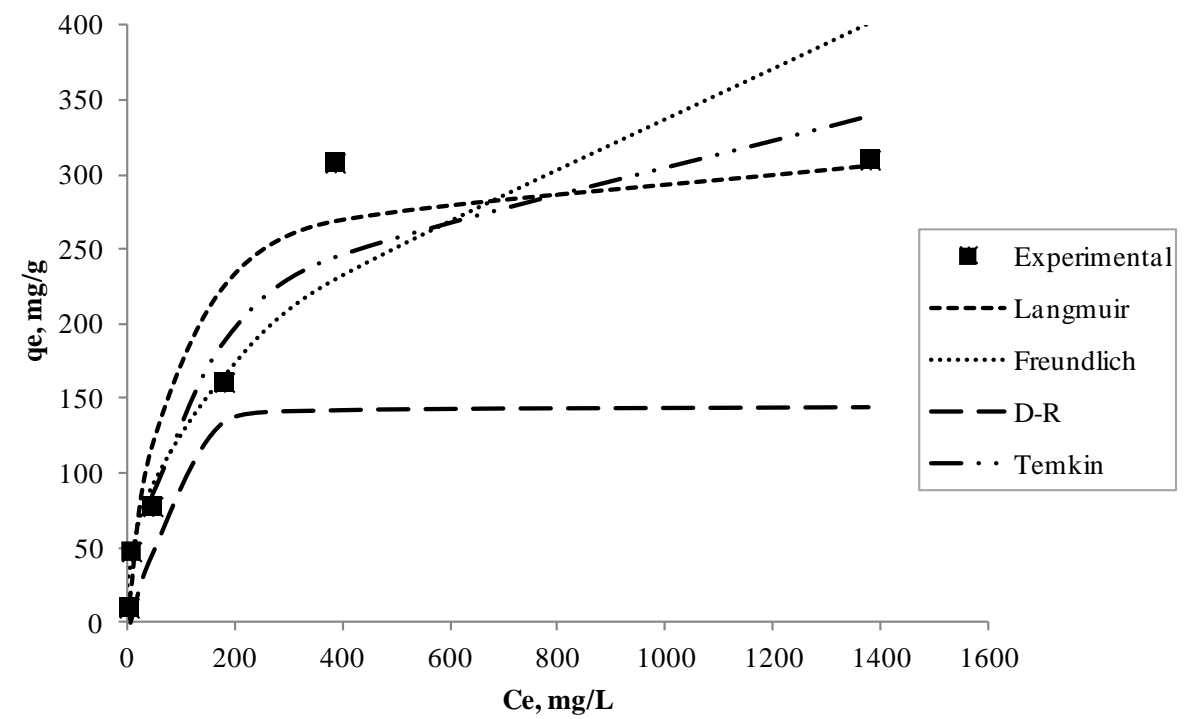

Şekil 8. Kurşun adsorpsiyonunda izoterm eğrileri

Tablo 3. Kurşun adsorpsiyonu için izoterm parametreleri

\begin{tabular}{|l|l|l|l|}
\hline \multirow{2}{*}{ İzotermler } & \multicolumn{3}{|c|}{ Parametreler } \\
\cline { 2 - 4 } & $q \max (\mathrm{mg} / \mathrm{g})$ & $b(\mathrm{~L} / \mathrm{mg})$ & $R^{2}$ \\
\cline { 2 - 4 } & 327.8 & 0.013 & 0.98 \\
\hline \multirow{2}{*}{ Freundlich } & $K f(\mathrm{~L} / \mathrm{mg})$ & $n$ & $R^{2}$ \\
\cline { 2 - 4 } & 16.79 & 2.28 & 0.96 \\
\hline \multirow{2}{*}{ Temkin } & $b_{t}$ & $K_{t}(\mathrm{~L} / \mathrm{mg})$ & $R^{2}$ \\
\cline { 2 - 4 } & 60.31 & 0.060 & 0.86 \\
\hline \multirow{2}{*}{ D-R } & $q s(\mathrm{kj} / \mathrm{mol})$ & $E \mathrm{Kj} / \mathrm{mol}$ & $R^{2}$ \\
\cline { 2 - 4 } & 144.4 & 1.17 & 0.70 \\
\hline
\end{tabular}


$\mathrm{K}_{\mathrm{c}}$ değeri bir dağılım sabiti olup hesaplanmasında bir çok yaklaşım kullanılmaktadır. Bazı araştırmacılar Langmuir izoterminden hesaplanan b sabitini kullanarak Gibbs serbest enerjisini hesaplamış olsa da bu durum sadece aynı başlangıç konsantrasyonları ile yapılan deneyler için kullanılabileceğini belirtmişlerdir [19]. Farklı başlangıç konsantrasyonları içeren bir sistemde dağılım sabitini hesaplamak için; $\mathrm{K}=$ qe/ce eşitliği kullanılır. Bu eşitliğin qe'ye karşı çizilmesi ile eğrinin kesme noktasından Kc sabiti bulunabilir [20]. Bulunan $\mathrm{K}_{\mathrm{c}}$ değerinden Eşitlik 4'de verilen formülden hesaplanan adsorpsiyon serbest enerjisi $\Delta \mathrm{G}_{\text {adss }}^{\mathrm{a}}$, değeri hesaplanmıştır. $\Delta \mathrm{G}^{\mathrm{o}}$ ads değeri, deneysel koşullar altında, adsorpsiyon sürecinin istemli olup olmadığını belirler [19]. Bir tepkimenin kendiliğinden gerçekleşmesi tepkime serbest enerjisinin $(\Delta \mathrm{G})$ işaretine bağlıdır. Gibbs serbest enerjisinin negatif işaretli olduğu koşullarda mutlak değerinin büyüklüğü oranında kendiliğinden gerçekleşme yönünde isteklidir. $\mathrm{Bu}$ araştırmada çalışılan $\mathrm{Pb}$ iyonlarının kömür yıkama atıklarına adsorpsiyonunda $293 \mathrm{~K}^{\prime} \mathrm{de}, \Delta \mathrm{G}^{\mathrm{o}}$ ads değeri negatif bulunmuştur $\left(-6.17 \mathrm{~kJ} . \mathrm{mol}^{-1}\right)$.

\section{SONUÇLAR}

Yapılan çalışma sonucunda kömür yıkama atıkları kullanılarak $\mathrm{Cu}, \mathrm{Zn}, \mathrm{Cd}$ ve $\mathrm{Pb}$ metal iyonlarının adsorpsiyon prosesi ile gideriminin mümkün olduğu bulunmuştur. Metal gideriminin $\mathrm{pH}$ 3'ün üzerinde her $\mathrm{pH}$ 'da gerçekleşebildiği, her $\mathrm{pH}$ değerinde adsorpsiyonun metallerin uzaklaştırılmasında çok etkili olduğu ancak $\mathrm{pH}$ yükseldikçe çöktürmenin de etkili olduğu bulunmuştur. Ancak alkali pH'larda hiçbir iyonla sadece çöktürme ile tam bir giderim sağlanamamış, adsorpsiyonun da etkili olduğu görülmüştür (kurşun hariç). Adsorpsiyon mekanizmasının incelenmesi amacıyla temas süresi ve başlangıç iyon konsantrasyonu deneyleri $\mathrm{Pb}$ iyonu ile yürütülmüştür. Buna göre $\mathrm{Pb}$ iyonu ile kömür yıkama atıkları temas süresi arttıkça adsorpsiyon kapasitesi artmış, 24 saat sonunda \%83 giderim verimi elde edilmiştir. Başlangıç iyon konsantrasyonu ise $20 \mathrm{mg} / \mathrm{L}$ 'den 2000 mg/L'e kadar çıkarılmış, kömür yıkama atıklarının $310 \mathrm{mg} / \mathrm{g}$ adsorplama kapasitesi olduğu bulunmuştur. Elde edilen sonuçların Langmuir ve Fredundlich izoterm modellerine uygun olduğu görülmüş olup, en yüksek korelasyon katsayısı Langmuir modelinde elde edilmiştir. Dubinin-Radushkevich (D-R) izotermi ile adsorpsiyonun fiziksel olduğu bulunmuş, Gibss serbest enerjisi hesaplandiğında ise reaksiyonun kendiliğinden geliştiği bulunmuştur. Sonuç olarak bu çalışma ile kömür yıkama atıklarının yüksek adsorpsiyon kapasitesine sahip olduğu ve bilinen ticari adsorbentlere karşı düşük maliyetli bir alternatif olabileceği düşünülmektedir.

\section{KAYNAKLAR}

[1] LOTTERMOSER, B.G. "Mine Wastes Characterization, Treatment and Environmental Impacts" Third Edition, Springer-Verlag Berlin Heidelberg, ISBN 978-3-642-12418-1, 2010.

[2] SHEN H., FORSSBERG. E. "An overview of recovery of metals from slags", Waste Management 23, 933949, 2003.

[3] ECKENFELDER, W.W.JR. "Industrial Water Pollution Control”, Second Edition, McGraw-Hill International Editions, 1989

[4] JUANG, R.S. WU, F.C., TSENG R.L. "The Ability of Activated Clay for the Adsorption of Dyes from Aqueous Solutions" Environmental Technology, 18: $\underline{5}, 25-531,1997$.

[5] ALYÜZ, B., VELİ, S. "Low-Cost Adsorbans Used In Heavy Metal Contaminated Waste Water Treatment", Journal of Engineering and Natural Sciences 3, 94-105, 2005.

[6] BABEL S., KURNIAWAN T.A. "Low- cost adsorbents for heavy metal uptake from contaminated water", Journal of Hazardous Material, 9, 219-243, 2003.

[7] YENIAL, Ü., BULUT, G. "Utilization of mineral wastes for wastewater treatment", Proceedings of XVI Balkan Mineral Processing Congress 979-986, Belgrade Serbia, June 17-19, 2015.

[8] NAMLI S., YENIAL, Ü., BULUT, G. "Arsenic Removal by Aluminium Industry Waste”, IWA 6th Eastern European Young Water Professionals Conference "East meets West" 926-933, Istanbul, Turkey 28 - 30 May 2014,

[9] BULUT, G., YENIAL, Ü., EMIROĞLU E., SIRKECI, A.A. “Arsenic Removal from Aqueous Solution Using Pyrite", Journal of Cleaner Production, 84, 526-532, 2014.

[10] http://www.enerji.gov.tr/tr-TR/Sayfalar/Komur (erişim tarihi: 11.08.2017)

[11] ATEŞOK, G., "Kömür Hazırlama Ve Teknolojisi”. Yurt Madenciliği Geliştirme Vakfi Yayınları ISBN NO: 975-7946-22-2, 2004. 
[12] ARPA, Ç., BAŞYILMAZ, E., BEKTAŞ, S., GENÇ, Ö., YÜRÜM Y., "Cation exchange properties of low rank Turkish coals: removal of $\mathrm{Hg}, \mathrm{Cd}$ and $\mathrm{Pb}$ from waste water", Fuel Processing Technology, 68, 2, 111 $120,2000$.

[13] UÇURUM, M., "Lavvar Tesisi Besleme Malı, Ara Ürün ve Atığının Ağır Metallerin Uzaklaştırılmasında Adsorbent Olarak Kullanımı" Madencilik, 47, 3, 43-48, 2008.

[14] LANGMUIR, I., "The constitution and fundamental properties of solids and liquids. Part I. Solids", J. Am. Chem. Soc. 38 2221-2295, 1916.

[15] FREUNDLICH, H., "Over the adsorption in solution", Z. Phys. Chem. 57 385-470, 1906.

[16] DUBININ, M.M., RADUSHKEVICH, L.V., "Proc. Acad. Sci”. USSR 55 331-333, 1947.

[17] TEMKIN, M.I., PYZHEV, V., "Kinetics of ammonia synthesis on promoted iron catalysts", Acta Physicochimica USSR 12, 327-356, 1940.

[18] WEBBER, T.W., CHAKKRAVORTI, R.K., "Pore and Solid Diffusion Models For Fixed-Bed Adsorbers". Alche Journal 20, 228-238, 1974.

[19] ANASTOPOULOS, I., KYZA, G.Z. "Are the thermodynamic parameters correctly estimated in liquidphase adsorption phenomena?", Journal of Molecular Liquids 218 174- 185, 2016.

[20] CHANG, R., "Chemistry", Fifth Edition, McGraw-Hill, USA, 736-758, 1994. 